\title{
An Integrated Desertification Vulnerability Index for Khorasan-Razavi, Iran
}

\author{
M. Pashaei, A. Rashki, Adel Sepehr* \\ Department of Desert and Arid Zone Management, Ferdowsi University of Mashhad, Iran
}

Copyright $(2017$ by authors, all rights reserved. Authors agree that this article remains permanently open access under the terms of the Creative Commons Attribution License 4.0 International License

\begin{abstract}
In recent decades' desertification as objectively the degradation of the ecosystems in arid, semi-arid, and dry sub-humid areas of the wide range of Iran with area more than 85 percent arid and semi-arid area is derived. The purpose of this study is to present an integrated index for vulnerability assessment of desertification based on imagery data at Khorasan Razavi province. At the first was prepared a land cover map of the province for two periods; 2000 and 2013, which was classified in 6 class involving agricultural, pasture, shrub lands, residential areas, desert, and forest. We applied remotely-sensor indices regarding the enhanced vegetation index (EVI), precipitation, soil salinity (SI), evapotranspiration, soil moisture, and land surface temperature (LST), to create an integrated desertification index (IDI). The degree of desertification vulnerability was considered along 14 years from 2000-2014. The results showed that more than 60 percent area of the province is very high and high vulnerable to desertification. Approximately 22\% are resistant ecosystems and about $18 \%$ classified in medium vulnerable class. Results indicated that vegetation cover changes are a most effective index for desertification process. Evapotranspiration index shows maximum fluctuations during studied periods. The kappa coefficient was measured about 0.75 which confirm the validity of results.
\end{abstract}

Keywords Integrated Desertification Indicator, Desertification Vulnerability, EVI, Iran

\section{Introduction}

Desertification generally occurs in arid, semi-arid and dry sub-humid areas of the world. In other words, desertification is described as the overall destruction on land, loss or destruction of the soil productivity and plant growth due to human interference and natural factors [1]. Desertification is a phenomenon that the United Nations officially recognized it as a global problem in the United
Nations summit of combating desertification in 1977 in Nairobi and today the harmful effects of this phenomenon is proven a major economic, social and environmental problems for more than a billion people living in 100 countries.

Accordingly, desertification is the actual collapse of ecosystems in areas where environmental changes and disturbances do not allow balance in these ecosystems, which are more vulnerable to such changes. As a result, the resilience of ecosystems in arid and semiarid regions shows a delay regarding response to outgoing changes in their environment [2].

The consequences of desertification involve many problems such as the loss of fertile land, reduction biomass in the forests, reduction of pastures and fertile plains, a decline of groundwater and surface water loss, salinization of land and declining quality of water resources, which brings irreparable damages.

In recent years, changes in land use and other human activities reduced the resilience of ecosystems in many parts of the Iran country and exacerbated the destruction of environmental resources. In FAO-UNEP (2015), Iran was included among countries that natural agricultural lands and areas are heavily affected by erosion and degradation [2]. Desertification monitoring and mapping are needed to control and combat desertification process. Many Activities and research have been done in assessing the extent of desertification, including direct observation, measurement, using remote sensing science and experimental equations. In particular, most of the efforts were made to implement and use a quantitative method to assess desertification using the concepts and definition of the indicators. However, these indicators have often trouble in measuring or observing complex processes or are not able to offer a plan to predict the desertification risk.

Therefore, offering management strategies, long-term plan to control desertification, land use plans and sustainable development are necessary more than ever. Management practices should be in a way that desertification always is considered as an environmental 
hazard, in other words, activities should be in the form of risk management, before the occurrence of a risk to human and financial losses. A desertification indicator system can be useful to handle a risk management for this hazard [3].

To develop a method for assessing and mapping of desertification (both the present situation and risk status) and for the development of controlling projects and programs, it is required to identify processes of desertification, factors affecting the development of the processes and criteria and indicators in the process of desertification. About fight against desertification Environment Agency of Europe, suggests using the indices as the amount of information effective in a phenomenon. The indices have little information on the occurrence of certain situations or help explaining how to study their evolution over time and the place. Indicators are usually effective in describing the characteristics of the phenomena, except some of the complex processes that are difficult to measure and observe them [4].

Use of one indicator alone could not suggest an accurate picture of the destruction or occurring events or is associated with error, misinterpretation, and chance because it only shows a single factor affecting degradation and its effects. The combination of several indicators together presents a more comprehensive and consistent understanding of the terms of desertification [5]. Sometimes the use of indicators is limited in time or place, but with the use of remote sensing, we can use more parameters in the temporal and spatial scale. Methods of remote sensing made it possible to achieve information of large areas by sensors operating in multiple spectral bands, which are transmitted by aircraft and satellites. Spectral bands used by sensors covers part of the visible spectrum and the short wave (0.58-12.5) micrometers. The total information obtained from remote sensing technology compared with other data offers higher potential for diagnosis, monitoring, and assessment of desertification [6]. The advantages of remote sensing technology to other data collection methods include ability to increase the sampling, vast surface coverage, high spatial and temporal resolution and lower cost [7].

Given that desertification begins slowly than other harmful phenomena and observing and prediction of it is very difficult, therefore in this study a combination of indicators to assess desertification using remote sensing data was used. Sepehr and Parvian [2], Desertification vulnerability map and prioritizing the strategies in ecosystems of Khorasan Razavi province based on PROMETHEE algorithm was developed. In this study, based on land use changes during 1990-2012, desertification vulnerability map was prepared using the PROMETHEE algorithm and main criteria of desertification for the year 2012. The results revealed that 91.7 percent of the province is within the high vulnerable class, 2.36 percent is in average vulnerable class and 5.85 percent is located in low vulnerable class.

Santini et al. [8] evaluated the risk of desertification by using a combination of indicators in GIS in the region of Sardinia (Italy). The six most important factor driving the desertification (excessive livestock grazing, vegetation, soil fertility, water erosion, wind erosion, salinization of water) were analyzed in two different periods and by using IDI. The results showed that overgrazing and erosion are the most important factors in the process of desertification in the study area.

Salvati et al. [9] used a combined index of five index changes (climate, land use, vegetation, territory, and population) in two different periods in order to determine Land Vulnerability Index (LVI) in Italy. The results showed that dry areas of southern Italy are more vulnerable due to land management practices, agricultural intensification, population pressure, and the physical destruction of the environment is in these areas.

Hadeel et al. [10] with remote sensing and GIS techniques examined the vulnerability of Basra in southern Iraq to desertification. The layers of soil, vegetation, climate and the sand move, were main data needed to estimate desertification index. Information obtained in the detection of changes indicated that in this area, sand move increased from 4118.3 to 4558.1 and most sensitive areas to Sandy desertification in the West- South parts of the province of Basra, which represents $61.9 \%$ of the region. The rest of the southern part of this area were relatively sensitive to desertification, which represents a total area of $18.9 \%$ and the northern parts of the study area with very low sensitivity and low desertification, which represent $10.7 \%$ and 8.5 percent of the total study area.

Salvati et al. [11] examined desertification risk during land use changes and environmental resilience in Basilicata, Italy. In this study, the impact of the land vulnerability to land use change (LUCS) in period 1975-2006 and desertification in two coastal sites in southern Italy were analyzed. The results showed low vulnerability to desertification in the forest and semi-natural areas and the high vulnerability of urban and agricultural areas to desertification.

Sepehr et al. [12] evaluated desertification of Khorasan Razavi province by using factors that reflect the ecological resilience of the region. In this study, the factors of soil erosion, the erosion of rainfall, topography and land cover were used to assess the risk of desertification. Finally, the map of the vulnerability of Khorasan Razavi province was prepared by multiplying factors of vulnerability to desertification. Results showed that about $44 \%$ of the area under study is in high-class vulnerability to desertification; in addition, the results depicted the effectiveness of vegetation factor in rising the potential of the resilience of Khorasan Razavi region in response to irregularities of the ecosystem.

Molinari [13] in study evaluated the vulnerability and risk of desertification by using the geographic information system (GIS) in Sardinia, Italy. The results of vegetation, soil degradation, water and wind erosion, water salinization 
and overgrazing on the two time periods (past and present) indicated that the central part of the southeast of Sardinia is more vulnerable to desertification.

Vorovencii [1] did a study entitled "Assessing and monitoring desertification in Romania", using data from Landsat and the Analytic Hierarchy Process in five periods 1987, 1994, 2000, 2001 and 2014. In the study, Modified Soil Adjust Vegetation Index (MSAVI1), Modified Soil Differential Index (MSDI) and albedo were used; the results of this study showed that the risk of desertification is associated with a high temperature as the main cause of deforestation and irrigation systems, and partly segmentation of agricultural land and deforestation.

Krishnan et al. [14] evaluated the effects of natural factors in Tamil Nadu desertification using remote sensing data. In this study, the rainfall data of TRMM satellite, evapotranspiration and MODIS net primary production (NPP), DEM data of ASTER satellites for 2000-2012 were used and then based on AHP method every index was weighted. The results showed that 18.17 percent was in very sensitive class to desertification in parts of the southwest area, 96.26 percent was in very intense class, 63.93 percent was in average class, 3.83 percent was in low sensitive class, and 4.8 percent was located in the very low class.

Salvati et al. [15] using Complex Adaptive Systems (CAS) examined soil degradation and desertification in Italy. In this study, the Integrated Framework of CAS in the years $1960,2000,2010$, were used to investigate spatiotemporal changes in indices for the assessment of desertification. The results showed a significant correlation between the indicators of soil level and land degradation. In southern Italy, there was a higher level of soil degradation and a higher level of sensitivity, while in northern Italy, there was a moderate from degradation and sensitivity to desertification.

Pina et al. [16] using Integration of remote sensing techniques for monitoring desertification in Mexico. In this study, Landsat TM images were used to compute the Normalized Difference Vegetation Index (NDVI), Bare-Soil Index (BSI), and albedo. A change vector analysis (CVA) examined changes in the direction and magnitude of indicators during the period 1993-2011. The results indicated that in the semiarid zone of the state of Querétaro, $48.3 \%$ of land use corresponds with agricultural areas; $2.7 \%$ of the area does not present any degree of desertification, while $49 \%$ presents the following degrees of desertification: $5.5 \%$ extreme, $10.9 \%$ severe, $18.9 \%$ moderate, and $13.7 \%$ low.

Lamchin et al. [17] did a study entitled "Assessment of land cover change and desertification using remote sensing technology in a local region of Mongolia”. In this study, a quantitative method for assessing land cover change and desertification assessment was developed using Landsat $\mathrm{TM} / \mathrm{ETM}^{+}$data on a local scale. In this method, NDVI, TGSI (Topsoil Grain Size Index), and land surface albedo were selected as indicators for representing land surface conditions from vegetation biomass, landscape pattern, and micrometeorology. Also, a Decision Tree (DT) approach was used to assess the land cover change and desertification in 1990, 2002 and 2011. Analysis showed that desertification of the study area is increasing each year; in the desertification map for 1990-2002, there is a decrease in areas of zero and low desertification, and an increase in areas of high and severe desertification from 2002 to 2011, areas of non-desertification increased significantly, with areas of severe desertification also exhibiting increase, while areas of medium and high desertification demonstrated little change.

Boitt and odima [18] evaluated desertification dynamics in Machakos County by using NDVI, TGSI (Topsoil Grain Size Index) and Albedo factors. The period of this assessment was between 1990 and 2010. It is realized that desertification can be mapped using the methods of NDVI, TGSI, and Albedo. Environmental, human and social activities are factors that determine the desertification of a given area or region. The aim of this study is to provide a combined index of desertification vulnerability assessment based on remote sensing data is in Khorasan Razavi. This paper aims to assess Khorasan Razavi degree of vulnerability to desertification based on an integrated model of desertification IDI.

\section{Materials and Methods}

Razavi Khorasan Province with an area of about 128,430 square kilometers, and within the coordinates 56 degrees 19 minutes to 61 degrees 16 minutes east longitude and 33 degrees 52 minutes north latitude to 37 degrees and 42 minutes, is including much of the arid and semi-arid with an average rainfall of about $210 \mathrm{~mm}$. $60 \%$ of the area is derived from arid and semi-arid areas. Also to the perspective of climate and elevation gradient, as we move forward from north to south, along with reducing the height of the rainfall is reduced and instead the dominant erosion processes, the aspect area to change the landscape desert ecosystems. Thus the province can be in terms of vulnerability to desertification and soil erosion processes are prone regions in Iran. Figure 1 shows the location of Khorasan Razavi provided by MODIS imagery data. 


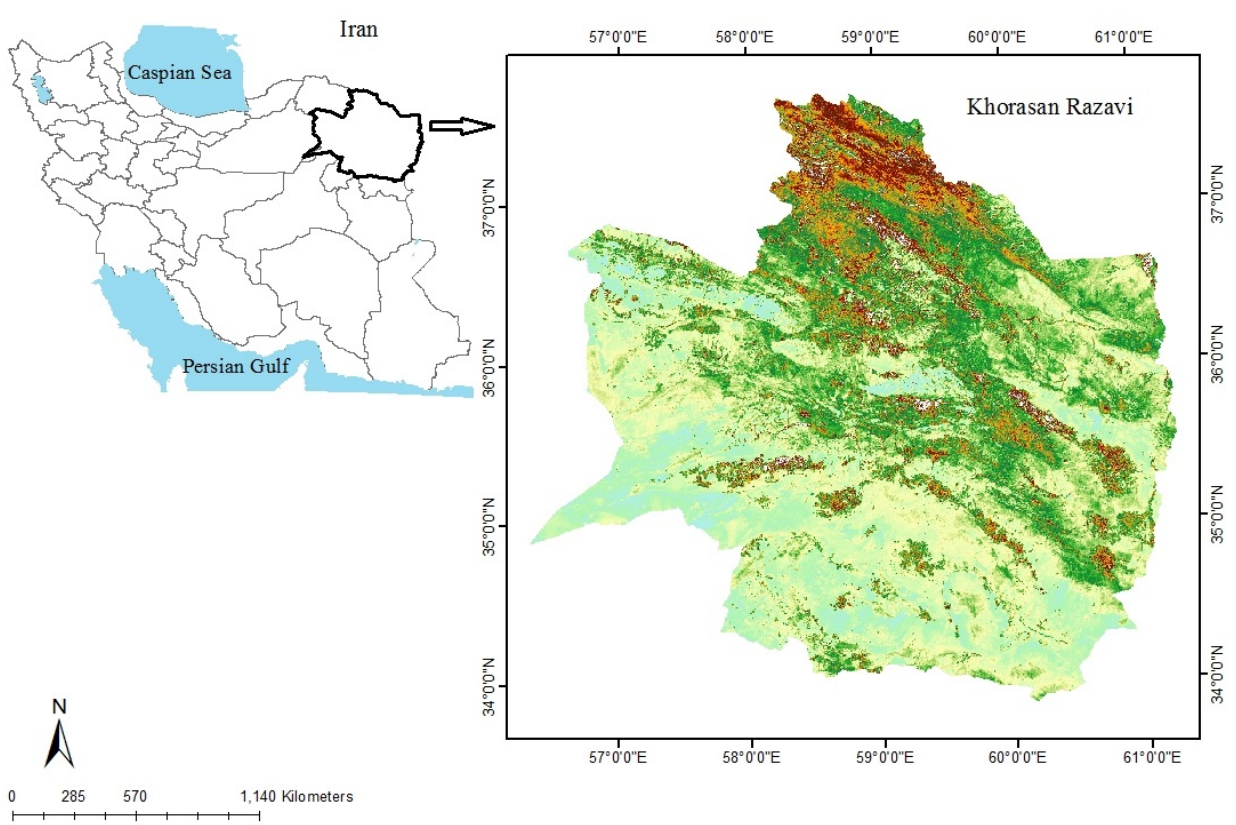

Figure 1. The position of Khorasan Razavi

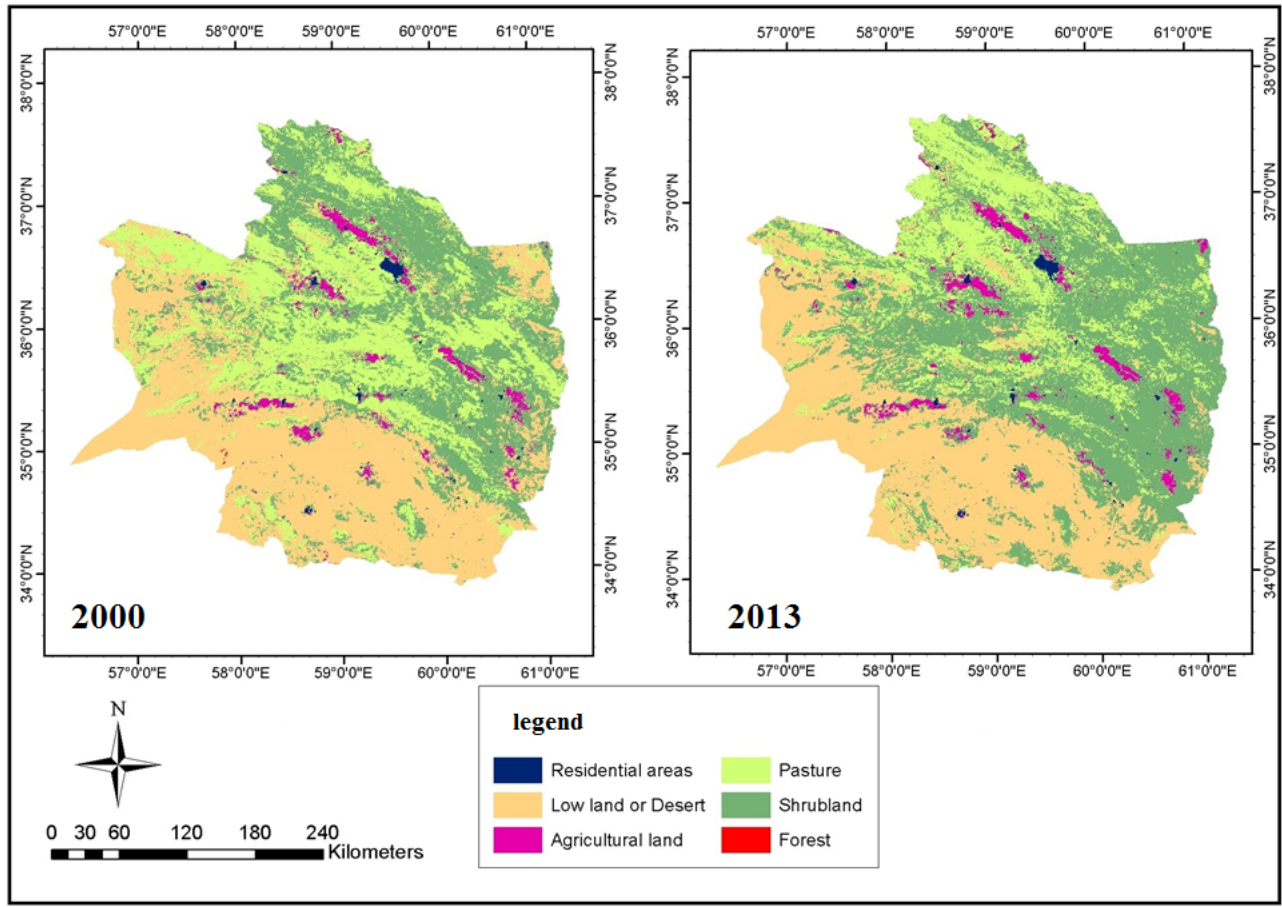

Figure 2. Land cover map Razavi Khorasan Province

\section{Methodology}

In this study to provide a combined index of desertification vulnerability assessment based on remote sensing data in Khorasan Razavi, the study was conducted in three phases. The first phase consists of mapping land cover map of the province as the work unit, the second phase was a selection of the assessment indicators and data analysis, and the third phase was mapping and assessing the degree of vulnerability of the of desertification based on IDI model. Only Santini et al. [8] used this model to assess the risk of desertification in Sardinia Italy. Parameters examined in this study include excessive livestock grazing, vegetation, soil fertility, water erosion, wind erosion, water salinization, which were examined at two different periods 1990-1994, 2003- 2007 and eventually were combined based on IDI, according to equation (8). For the first time, 
IDI algorithm was used for assessing the degree of vulnerability in Khorasan Razavi Province, according to local conditions and factors used in assessing desertification (rainfall, evapotranspiration, vegetation, soil salinity, soil moisture and land surface temperature) and based on the provincial land cover map.

The First step: Choosing Land Unit Map-LUM (in this research land cover was chosen)

The work unit means quantifying the performance of a system to use it as a reference unit [19]. In this study for the mapping land cover work unit, images of MODIS satellite, the combination of Terra and Aqua satellites (MCD12Q1) and the spatial resolution of $500 \mathrm{~m}$ for the years 2000 and 2013 were used. After preparing the mosaic, cropping and merging images in the ERDAS IMAGINE and classification in GIS software was done, finally, a land cover map for the years under study was prepared and classified in the six classes of agricultural lands, residential areas, pasture, shrubland, lowland or desert and forest cover.

Second step: Calculating effective indicators to assess desertification vulnerability

Biophysical Index changes due to fluctuations in variables during the period 2000-2013 with a range of 14 years as done. In addition, we tried to consider months, the nature of the index, climatic conditions and availability of data on the required scale. This phase of the study involves the collection and assessment of indicators and data in the work unit. Six vegetation index (EVI) of soil salinity, rainfall, evapotranspiration, soil moisture and temperature of the earth's surface were taken into account to determine the degree of vulnerability to desertification. Preparation all the layers of information at this stage was done using the ERDAS software 2013 version and Arc GIS (10.1). Calculation of the index of desertification was done as follows:

\section{Vegetation Index (EVI)}

Many indicators for monitoring vegetation are presented. One of the indicators is EVI, which was developed to remove the restrictions in the NDVI [20]. To calculate the vegetation index, the EVI index of MODIS, Terra (MOD13Q1) with a resolution of $250 \mathrm{~m}$ was used. Images Selection was considered in connection with the maximum growth for the month of June in 2000 and 2013. After preparing mosaics, cropping and integration of image improved map of vegetation index were prepared based on equation 1 . The index was classified to four classes of relatively low vegetation cover in $(<0.04)$, low $(0.1-0.04)$, average (0.2-0.1) and high (>0.2) [21].

$$
\mathrm{EVI}=2.5(\mathrm{NIR}-\mathrm{R}) /\left(\mathrm{NIR}+\mathrm{C}_{1} \mathrm{R}-\mathrm{C}_{2} \mathrm{BLUE}+\mathrm{L}\right)
$$

In this equation, EVI Enhanced Vegetation Index, NIR, R and BLUE atmospheric correction reflectance values $C_{1} \cdot C_{2}$ and $\mathrm{L}$ is the correction factor is atmospheric [20].

\section{Rainfall Index}

Rainfall is one of the most important factors that influence vegetation and thus desertification, particularly in arid and semi-arid ecosystems. Because the soil moisture conditions caused by rainfall in the area is very impressive in plant changes, drought monitoring and vegetation change and its impact on the region's sensitivity to desertification are the most important management tools in the ecosystems [22]. Calculation of the amount of Rainfall was performed with the help of TRMM data with a spatial resolution of 0.25 degree and based on the average amount of 7 months (October to June). The reason for this period is the influence of rainfall on vegetation in the year under study.

\section{Index Land Surface Temperature (LST)}

In order to assess desertification in the land, use of thermal bands for correct and accurate checking it is recommended. It is assumed, in areas with a higher risk of desertification soil moisture will be reduced and creates thermal stress at ground level, which leads to increase in air temperature. In order to calculate the surface temperature of the day for June (June) MODIS data from, Terra (MOD11CM1D) with a spatial resolution of $1 \mathrm{KM}$ for the years 2000, 2013 was used.

\section{Evapotranspiration Index}

Evapotranspiration is an important component of the water balance in arid and semi-arid and correct estimate for the optimal management of water resources is very important. In arid regions of Iran, each year, more than $80 \%$ of the total annual rainfall, which is about 80 billion $\mathrm{M}^{3}$, returns to the atmosphere through evaporation [23]. Thus any attempt to improve water use efficiency in areas affected by desertification processes must be based on reliable estimates of the evapotranspiration. In order to calculate evapotranspiration in the whole province of numeral Data MERRA, GLDAS_NOAH025_M and NOAH model was used. This data was used with spatial resolution 0.25 degrees (25 km) on the basis of June.

\section{Soil Moisture Index}

Soil moisture in the root zone called to the soil moisture at a depth of 30 to $100 \mathrm{~cm}$ above the soil surface. That is generally accessible by plant roots and moisture evaporation capability and its transfer to the air. Basically direct monitoring soil moisture and moisture Data extracting to form point Not only costly and time-consuming but is impractical on large surfaces. In the meantime, techniques based on remote sensing is excellence compared with spot metering or simulation models for the spatial resolution (less 
than $1 \mathrm{~km}$ ) and time (a few days) better, Easy operation and accuracy calculation of soil moisture [24].

In order to consider the impact of soil moisture on the vulnerability of the region to the desertification were considered of numeral data MERRA, GLDAS-MOS10-M with spatial resolution 0.25 degrees $(25 \mathrm{~km}$ ) for June.

\section{Soil Salinity Index (SI)}

Salinity is one of the most important factors affecting soil degradation and desertification is caused by natural or human-induced processes. To calculate the index were used of MODIS, Landsat satellite images, layer 4 (red band) 6 layers (blue band) satellites, Terra (MOD13Q1) with monthly temporal resolution and spatial resolution of $500 \mathrm{~m}$ in August 2013, and 2000.

After preparing the mosaic, cutting and separating the layers, soil salinity calculated using Equation 2 [25] in three class were classified low salinity $(0.17>)$, average salinity $(0.17-0.2)$ and high salinity $(0.2<)$ the area [26].

$$
\text { SI }=\sqrt{\text { BLUE*RED }}
$$

Finally, after calculated all indicators, as respects the pixel size of each index are different and the possibility of integration comparable to indices pixels with pixel size indicators studied work unit we will study was changed. Resample method was used to change the pixel size images. Resample method was used to change the image pixel size [27].

\section{Step Three: Representation Integrated Index Assessing the Vulnerability to Desertification of Khorasan Razavi Province Basis on the IDI}

This step includes describing the model used to assess the risk of desertification in the study area. At these step indicators considered were mapped in assessing vulnerability to desertification, to get results in the application of GIS and ERDAS.

The final stage of the proposed method is consisting of integrated desertification index extraction (IDI) by use all the concepts mentioned above. Models and methods have been proposed to assess desertification in the world Including the assessment of desertification calculated using the geometric mean, for example, by Kosmas et al., 1999 Motroni et al., 2004 and or effective method of some indicators on desertification was implementation, for example, Grunblatt et al., 1992; Mouat et al. 1996, as well as the implementation model, was performance to determine desertification sensitive areas (ESA) by people like Embrinda et al., 2013 and Tupa et al. 2013 in different areas [8].

But The advantages of this model (ID) is not only described the terms and rate of the distribution of vulnerability to desertification areas, rather the desertification Monitoring over a period of time (past, present) and represents a risk of land degradation and desertification in different time periods that the most important feature of this model is to assess desertification. Other features of this model are to determine the most effective indicator of vulnerability to desertification, according to the weight given to each indicator to calculate the IDI model.

The analysis process consists of 4 steps is to implement an integrated model of IDI. At this stage, before calculating the IDI model, maps prepared at the second stage of preparation and calculation of data through GIS software and Zonal Statistical function put on the work unit (land cover map) that were prepared in the first stage. The study also overlaying the images based on pixel average algorithm.

\section{Step One: Normalized Indicator Results}

In this study, if the results of an index in the range between $[0,1]$ There is not a need to normalization otherwise using equation (3) can be dimensionless indicators.

$$
\left[\begin{array}{ccc}
a_{11} & \ldots & a_{1 n} \\
\vdots & \vdots & \vdots \\
a_{n 1} & \ldots & a_{n n}
\end{array}\right] \quad i, j=1,2, \ldots, n
$$

Calculate the normal matrix R $\left(=\left[\mathrm{r}_{\mathrm{ij}}\right]\right)$

$$
r_{i j}=a_{i j} / \sqrt{\sum_{j=1}^{n} a_{i j}^{2}}
$$

\section{Step Two: Determine the Index Changes in the period 2000-2013}

The step we calculated change between two time periods in 2000-2013. In order to change any parameters was prepared using the ERDAS software and change Detection menu.

\section{Step Three: Weighted Matrix Indicators}

At this stage to calculate the IDI need to weigh the indicators are that 2013 period index and index change for two periods of time.

Therefore, in this study to weight the index in the period in each of the six classes based on a work unit (land cover) was used of the weighting method based on Shannon entropy [28].

(4) Calculation $\mathrm{p}_{\mathrm{ij}}$

$$
\begin{gathered}
{\left[\begin{array}{ccc}
a_{11} & \ldots & a_{1 n} \\
\vdots & \vdots & \vdots \\
a_{n 1} & \ldots & a_{n n}
\end{array}\right] \quad i, \quad j=1,2, \ldots, n} \\
p_{i j}=a_{i j} / \sum_{i}^{m}=1 a_{i j}
\end{gathered}
$$

(5) Calculate the amount of entropy $E_{j}$

$$
E_{j}=-K \quad \sum_{i=1}^{m}\left[p_{i j} \operatorname{lnp}_{i j}\right]
$$

(6) Calculate the amount of unreliability $d_{j}$

$$
\mathrm{d}_{\mathrm{j}}=1-\mathrm{E}_{\mathrm{j}}
$$


(7) Calculate weights $\mathrm{w}_{\mathrm{j}}$

$$
\mathrm{w}_{\mathrm{j}}=\mathrm{d}_{\mathrm{j}} / \sum_{\mathrm{j}=1}^{\mathrm{n}} \mathrm{d}_{\mathrm{j}}
$$

Indicators calculated at the step two multiplication in the weighting factor and at this stage was determined the weight of each index.

\section{Step Four: Presentation Integrated Index IDI Model}

The final stage of desertification indicators is to provide an integrated desertification Index (IDI) that is calculated using the following equation: The algorithm used in the model to estimate the risk of desertification is based on the geometric mean of exponential functions of desertification indicators.

$$
\mathrm{IDI}=\frac{1}{\mathrm{~N}} \sum_{\mathrm{i}=1}^{\mathrm{N}}\left[\frac{\mathrm{e}^{\mathrm{P} \Delta I \mathrm{D}_{\mathrm{i}}{ }^{*} \Delta \mathrm{I} \mathrm{D}_{\mathrm{i}}}}{\mathrm{e}} * \frac{\mathrm{e}^{\mathrm{P}_{\mathrm{P}} D_{\mathrm{i}}^{*}{ }^{*} \mathrm{D}_{\mathrm{i}}}}{\mathrm{e}}\right]
$$

Where $N$ is the number of considered processes, $i$ represents the single process, $I D_{i}$ represents the degradation index of the ith process for the present (2013) and $\Delta I D_{i}$ ndicates the variation from the past (2000-2013) of the ith degradation index. Finally $P_{I D_{i}}$ is the weight assigned to the process $i$ (2013), whereas $P_{\Delta I D_{i}}$ is the weight assigned to the variation of the index $\mathrm{i}$ between the two considered periods (2000-2013). $e$ Euler's constant and $\mathrm{e}$ is approximately equal to 2.718 .

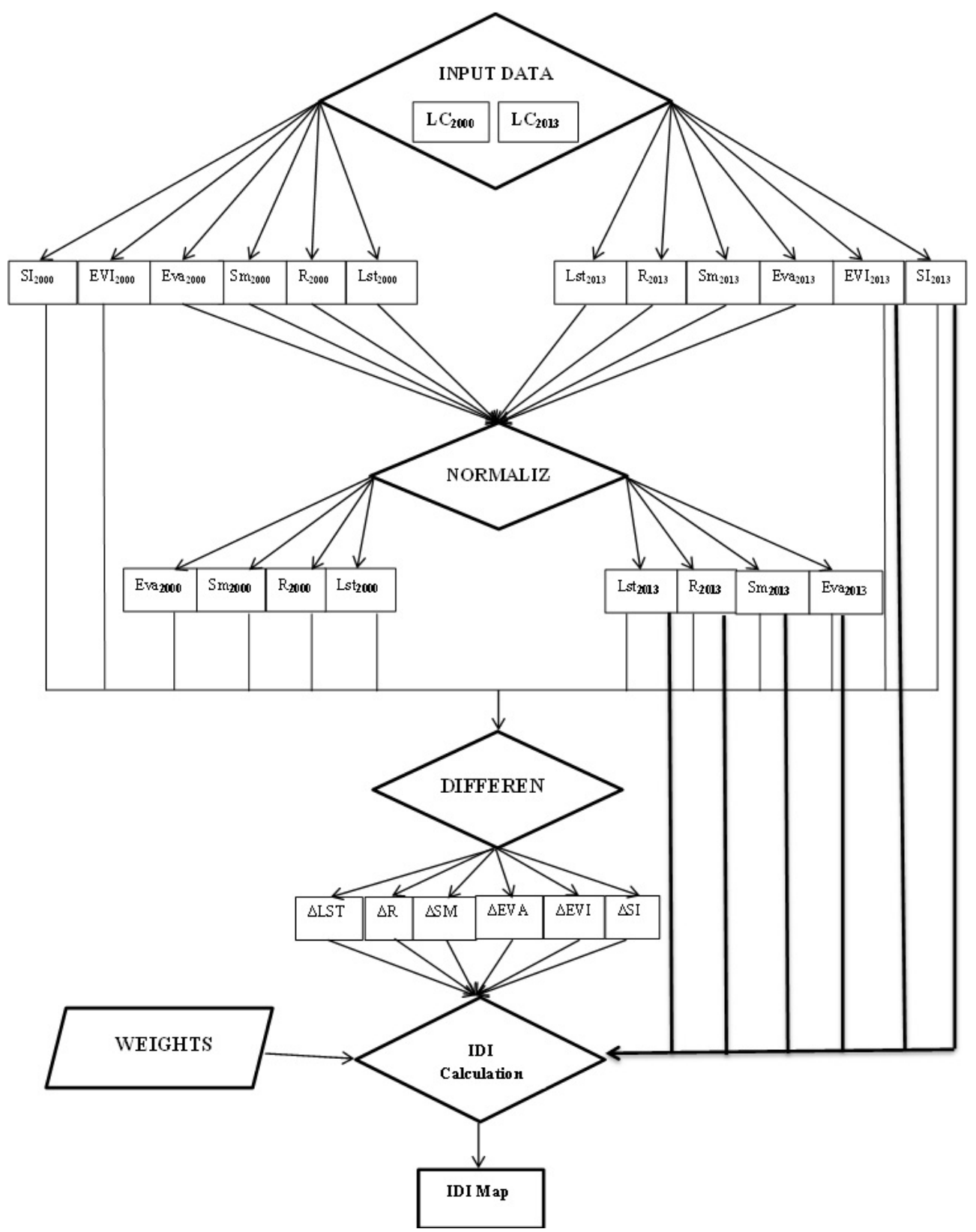

Figure 3. stages of the computational method IDI. Figure LC is representing a work unit (map land cover) and LST, R, Sm, Eva, EVI and SI indexes respectively is representing the land surface temperature, rainfall, soil moisture, evapotranspiration, vegetation and soil salinity. 


\section{Accuracy Estimation}

Estimation of accuracy to understand and apply the results in decision-making is very important. The most common accuracy estimation parameters, including overall accuracy, manufacturing precision and the accuracy of the user, are kappa coefficient. To evaluate the accuracy of IDI model, kappa coefficient based on resilience map of Khorasan Razavi to desertification prepared by Tervonen et al. [21] was used.

Resilience map of the province to desertification has been achieved using ETM +, TM images and based on the land use map of the province and was classified in 3 class of protected areas against desertification, non-protected areas and semi-protected area against desertification. To determine overall kappa coefficient of IDI based on resilience map of the province to desertification, ERDAS IMAGINE software, Accuracy Assessment function with a random selection of about 200 points in the Khorasan Razavi province were used.

In general, the vulnerability of Khorasan Razavi calculated using IDI model based on remote sensing data could be shown in Figure.3.

\section{Results and Discussion}

Improved Vegetation index in the study area was between 0-0.85 in 2000 and 0-0.71in 2013 that almost in $60 \%$ of the area of the province this index is less than 0.1 . In other words, more than half of the province is covered with low vegetation. The salinity index at the provincial level was variable between 0-0.3 for the year 2000 and 2013 and about 80 percent of the region is in low salinity class.

The results of Mehta et al. [26], Jabbar [29] and albedo [30] confirmed the performance of salinity indicators used in this study to separate the soil salinity using Satellite images. The results of the combination and overlaying layers of land cover and studied six indicators with different functions for 2000 and 2013 were presented in Table 1. The investigation of the amount of each index in every class of land cover maps showed that low coverage class or Bayer in 2000 had the lowest amount of rainfall, soil moisture and vegetation, and the highest temperature and soil salinity. In terms of the five indicators of it had higher vulnerability compared to other land cover classes against desertification in 2000. For the year 2013, it was shown that precipitation, soil moisture, vegetation, evapotranspiration was at the lowest amount and temperature of the earth's surface, soil salinity was the highest amount for low coverage class in comparison with other land cover classes.

The weight and importance assigned to the indicators of 2013 and related changes in the period 2000-2013 are shown in Table 2.

Table 1. Shows a number of exponential indicators for work unit classes (land cover), respectively, for 2000 and 2013

\begin{tabular}{|c|c|c|c|c|c|c|}
\hline $\begin{array}{c}\text { Indicator } \\
\text { Land cover }\end{array}$ & $\begin{array}{c}\text { Land surface } \\
\text { temperature }\left({ }^{\circ} \mathrm{C}\right)\end{array}$ & Soil Salinity & Vegetation & $\begin{array}{c}\text { Evapotranspirati } \\
\text { on }(\mathrm{mm})\end{array}$ & $\begin{array}{c}\text { Soil moisture } \\
(\mathrm{mm})\end{array}$ & $\begin{array}{c}\text { Rainfall } \\
(\mathrm{mm})\end{array}$ \\
\hline \multirow{2}{*}{ Forest } & 46.524 & 0.129 & 0.0889 & 7.251 & 0.921 & 139.150 \\
& 42.438 & 0.0757 & 0.142 & 0.409 & 1.164 & 267.015 \\
\hline \multirow{2}{*}{ Agricultural lands } & 45.451 & 0.147 & 0.193 & 7.343 & 0.936 & 138.475 \\
& 42.207 & 0.134 & 0.202 & 0.393 & 1.186 & 247.137 \\
\hline \multirow{2}{*}{ Pasture } & 46.124 & 0.132 & 0.085 & 7.237 & 0.917 & 135.475 \\
& 41.747 & 0.129 & 0.120 & 0.445 & 1.214 & 260.833 \\
\hline \multirow{2}{*}{ Shrubland } & 45.925 & 0.157 & 0.097 & 7.284 & 0.960 & 139.041 \\
& 43.359 & 0.143 & 0.105 & 0.318 & 0.318 & $236 / 692$ \\
\hline \multirow{2}{*}{ residential areas } & 44.988 & 0.132 & 0.125 & 6.919 & 0.942 & 138.501 \\
& 41.504 & 0.136 & 0.133 & 0.436 & 1.197 & 240.567 \\
\hline
\end{tabular}

Table 2. The given weight to indicators of 2013 and their changes to the calculation of the IDI model

\begin{tabular}{|c|l|}
\hline Indicators and indicator changes in two periods & Weight \\
\hline Precipitation Index & 0.059 \\
\hline Change precipitation index & 0.221 \\
\hline Vegetation Index & 0.421 \\
\hline Change vegetation index & 0.179 \\
\hline Soil salinity index & 0.186 \\
\hline change Soil salinity index & 0.083 \\
\hline Soil moisture index & 0.023 \\
\hline Change soil moisture index & 0.067 \\
\hline Evapotranspiration index & 0.305 \\
\hline Change evapotranspiration index & 0.412 \\
\hline land surface temperature index & 0.006 \\
\hline Change land surface temperature index & 0.037 \\
\hline
\end{tabular}


As shown in the above table, the maximum weight assigned to the six indicators in this study for the year 2013 is related to vegetation index and index changes in two periods of evapotranspiration index, which indicates the degree of importance of the criteria in determining vulnerability to desertification in the area. Figure.4 shows the execution of steps 1 to 3 for soil salinity map in 2000 .

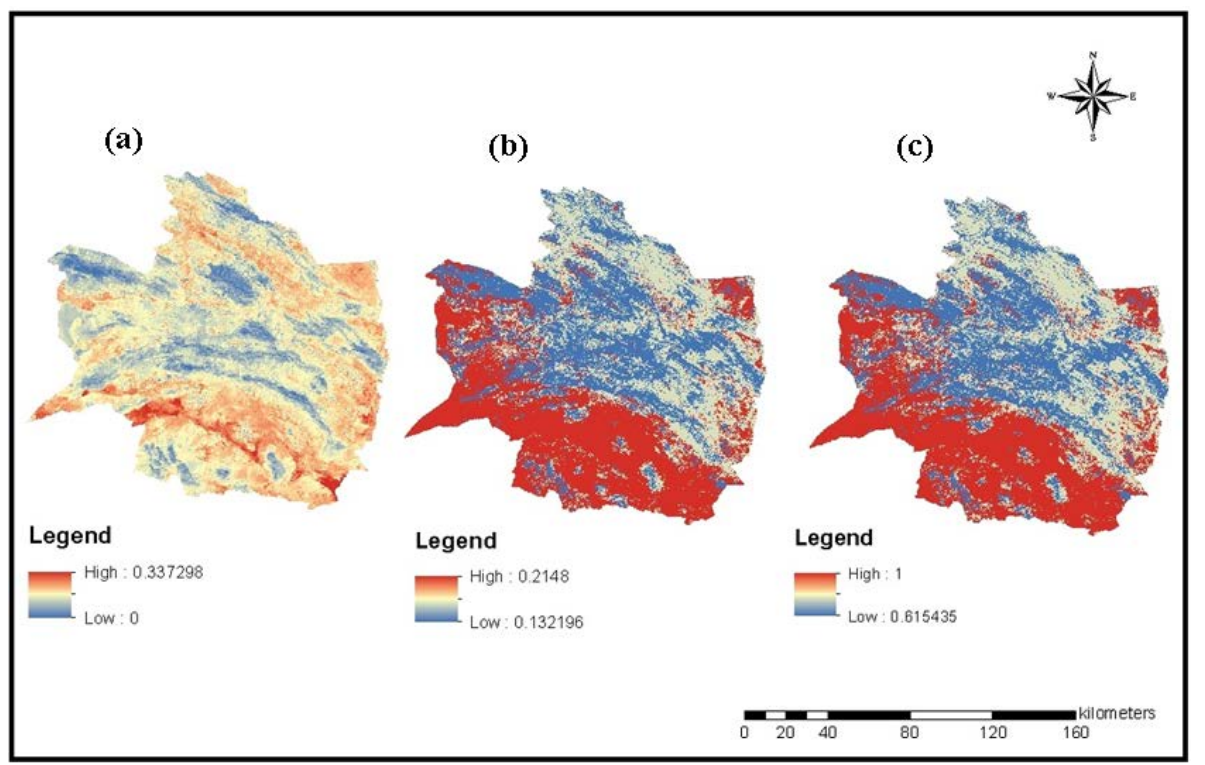

Figure 4. Show the results of the implementation steps 1 to 3 for the calculation of IDI model for salinity index (2000). Left map (a), is soil salinity map based on MODIS satellite images and the middle of the map (b), is overlaying maps of soil salinity maps and map work unit and map to the right (c), is Normalized maps of soil salinity.

Finally, after the implementation of the new model of IDI to determine the degree of vulnerability of Khorasan Razavi province to desertification, the results were at a range of values between 0.17-0.99 and then classified by Table 3 .

Table 3. Definition, and description of risk classes into which the map of IDI was divided

\begin{tabular}{|c|c|c|}
\hline Risk Class & Range of values Description & Description \\
\hline Very Low (Not subjected areas) & $0-0.15$ & $\begin{array}{c}\text { Areas where the critical factors are very low or absent, } \\
\text { with a good equilibrium between environmental land } \\
\text { socioeconomic components }\end{array}$ \\
\hline Low (Potential areas) & $0.15-0.3$ & $\begin{array}{c}\text { Areas menaced by desertification if it will be applying } \\
\text { wrong land management practices or when the adjacent } \\
\text { degraded areas influence produces severe problems. They } \\
\text { could be included abandoned lands not properly managed } \\
\text { Areas where every change in the delicate equilibrium } \\
\text { between the natural environment and human activities can } \\
\text { lead to desertification. }\end{array}$ \\
\hline Medium (Fragile areas) & $0.3-0.5$ & $\begin{array}{c}\text { Degraded lands characterized by a precarious equilibrium } \\
\text { between natural environment and human activities }\end{array}$ \\
\hline High (Critical areas) & $0.5-0.7$ & $\begin{array}{c}\text { Areas already highly degraded because of past wrong } \\
\text { management, representing a menace for surrounding areas } \\
\text { or with evident desertification processes. }\end{array}$ \\
\hline Very high (Degraded areas) & $0.7-1$ &
\end{tabular}

Source: Santini et al., 2010 
The results of the implementation of IDI determined that changes in land use during the 14 years, in classes of bushland, pasture and part of the low covering and Bayer, with the participation of destructive activities, led to advent of very high and high desertification vulnerability class, on the part of low coverage class, shrub land and pasture on the East, South East and Southwards (Sarakhs, Taybad, Khaf, Roshtkhar, Sabzevar, etc.). These areas had the highest vulnerability to desertification during the period of the study and almost 60 percent of the province was located in these classes of desertification located (Figure. 5). The main reasons are as following:

1. The area of the arid and semi-arid region and its special geographical position. 2. The time and duration of the high-speed monsoon winds in the province including in, Sarakhs, Sabzevar, Khaf, and effects of "Sistan” 120-days long winds. 3. Soil degradation due to change of land use, loss of soil fertility, reduction of soil depth due to water and wind erosion and lack of scientific principles in farms plowing, 4. Destruction of vegetation due to off-season overgrazing of pastures, destruction of water resources, which occurs due to the drop in underground aquifers, reduction the quality of water resources and increasing polluting minerals, increase of industrial and the bacterial pollution and increase of swamp lands because of incorrect irrigation.

According to the results, 22\% (25916.6 square kilometers) and 18 percent (23929.1 square kilometers) of region was in the middle and low vulnerability class to desertification (Table 4) that is consistent with the results of the Sepehr and Parvian [2] and Sepehr et al. [12] regarding the high vulnerability of province to desertification. The kappa was obtained to be 0.75 . High levels of kappa index of assessing the validity of the model, shows the reliability of this map.

As can be seen in figure.5, the highest vulnerability to desertification was in the eastern part of the province, such as Sarakhs, taybad, Torbat E Jam and Khaf, that is due to unfavorable climatic conditions in the eastern part of the province.

One of the major reasons for the region's high vulnerability to desertification of the eastern part of the province is due to bordering with Afghanistan and the lack of rehabilitation programs and reform in the country's natural resources that have added to the sensitivity and fragility of these areas that is consistent with the results of Boitt and Odima (2017) regarding the increase of desertification in the 10 years from 2000 to 2010 and The highest rate of desertification in MACHAKOS as well as in parts of north-eastern and south-western province [18].

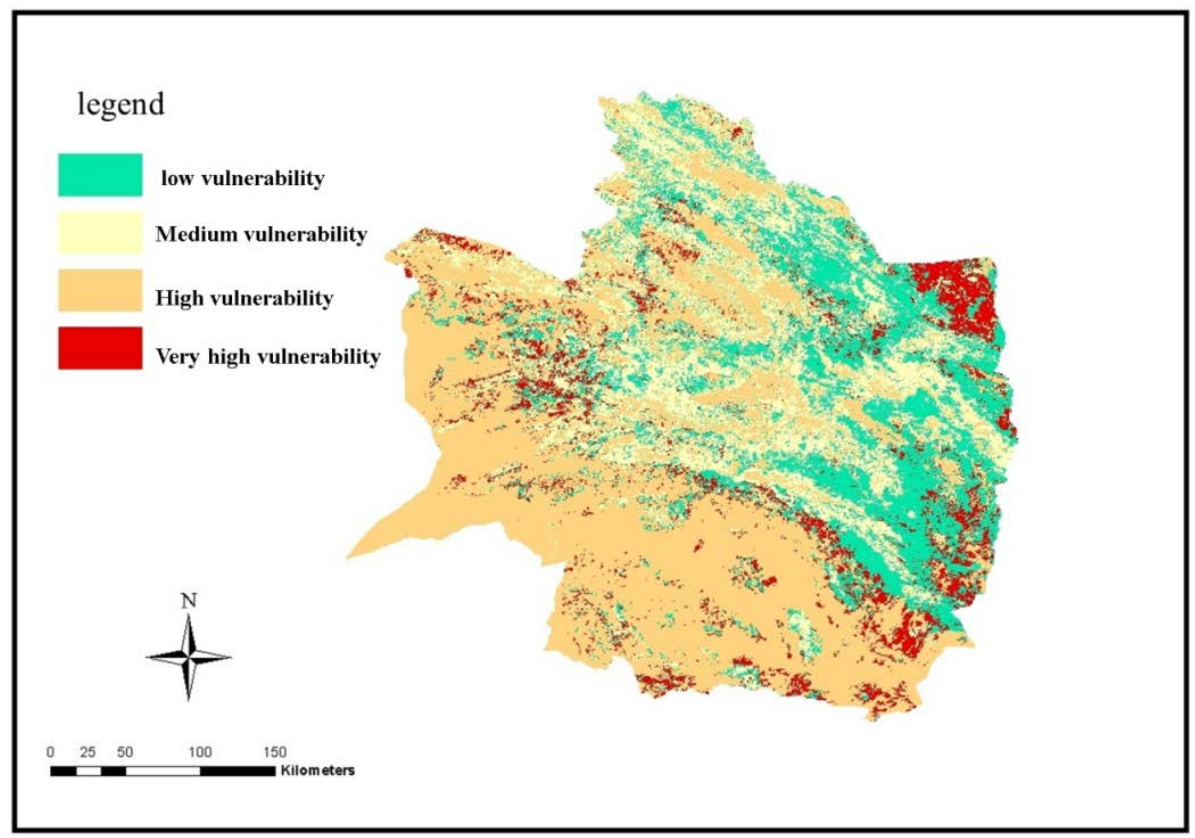

Figure 5. The final map vulnerability to desertification Razavi Khorasan Province during the period of 14 years based on the IDI model

Table 4. Area of Razavi Khorasan class vulnerability assessment based on the IDI model in 14 years

\begin{tabular}{|c|c|}
\hline \multicolumn{2}{|c|}{ The area of each class IDI based $\left(\mathrm{KM}^{\mathbf{2}}\right)$} \\
\hline Classes IDI & The amount of area \\
\hline Low vulnerability & 23929.1 \\
\hline Medium Vulnerability & 25916.6 \\
\hline High vulnerability & 56099.3 \\
\hline Very High vulnerability & $\mathbf{1 0 4 1 1 . 1}$ \\
\hline
\end{tabular}


Desertification vulnerability map of the province showed that despite the occupation of a significant portion of the area of the province with fragile ecosystems, a large part of the ecosystems under study in years of comparison of ecosystem vulnerability maps with the current land use map, confirmed the fact that major vulnerable ecosystems were located in low coverage or Bayer and pasture classes. Ecosystems that due to climate change, land use change, the exploitation, and destruction of vegetation, mismanagement of human activities in the future may depict a desert landscape to their societies that also in the study mahamane et al. (2015), regarding the monitoring desertification in the Tillabéry (Western Niger) landscape achieved such results. The results show that the landscape is highly fragmented (such as low coverage), indicating that the original landscape has been converted gradually into bare and desertified area [31].

In the study Lamchin et al. (2017), desertification has been increased in Mongolia from 2002 to 2011 because pasture is an important land cover type in the study area and pastureland-based beef farming in Mongolia increased the number of livestock animals during the last period. These cases were affected by the resilience of grassland and by forage use in this area. If this issue continues for a long time, farmers will have to respond the increase desertification in the future [17]. Table 4 shows the extent of desertification vulnerability in each class.

\section{Conclusions}

IDI model by taking into account the geometric mean of exponential functions of indices effective in the process of desertification, simultaneously and by assessing their feedbacks in relation to each other, determines the vulnerability of the area to desertification. To calculate this model, with determining the coefficient weight of each indicator and their changes it was shown that vegetation index was the most effective index in the year 2013 and the evapotranspiration index was most important indices for the changes in the period from 2000-2013, to determine the vulnerability of Khorasan Razavi province to desertification.

Low coverage class and Bayer, had the highest vulnerability to desertification during this period of 14 years. The classes were located in much of the province, especially the southern, eastern (Sarakhs) and the lowest vulnerability to desertification were in the northern areas (Dargaz, Fariman) and parts of the northeast areas. Generally, the use of IDI showed that this indicator due to the use of remote sensing data is a flexible and cost-effective way and it is a useful tool for assessing the degree of vulnerability index of desertification and the changes of this phenomenon in different time series. It is efficient and useful in dealing with complex management decisions.

\section{Acknowledgements}

The research was supported by grant 3-1505. The authors are many thanks from colleagues of natural resources and environment college of the Ferdowsi University of Mashhad for their support and cooperation during research steps.

\section{Author Contributions}

Mojgan Pashaei conducted the field work and contributed to the analysis of the data as well as in writing the first draft. Alireza Rashki was a supervisor for research. Adel Sepehr created an idea and developed the study design, supervised research and data analysis and contributed in revising the manuscript.

\section{Conflicts of Interest}

The authors declare no conflict of interests

\section{REFERENCES}

[1] I. Vorovencii. Assessing and Monitoring the risk of Desertification in Dobrogea, Romania, using Landsat data and Decision Tree Classifier, Journal of Environmental Monitoring and Assessment, Vol. 187, No. 4, 154-220, 2015.

[2] A. Sepehr, N. Parvian. Desertification Vulnerability Mapping and Prioritize Confronting Strategies in Khorasan Razavi Province Based on the Nartbh Pramsh Algorithm, Journal of Earth science research, Vol.2, No.8, 58-71, 2012.

[3] A. Sepehr, M. Ekhtesasi, A. Almodaresi. Development of Desertification Indicator System Base on DPSIR (Take advantages of Fuzzy-TOPSIS), Journal of Geography and Environmental Planning, Vol. 23, No.1, 9-11, 2012.

[4] J.L. Rubio, E. Bochet. Desertification Indicators as Diagnosis Criteria for Desertification Risk Assessment in Europe, Journal of Arid Environments, Vol. 39, No. 2, 113-120, 1998.

[5] M.R. Ekhtesasi, A. Sepehr. Method and Models of Desertification Assessment and Mapping. Yazd University, Iran, 2011.

[6] A. Shamsipour, K. Alavi Panah, H. mohammadi. The Efficiency Study of Thermal and Plants Indexes NOAA-AVHRR Satellite in Drought Analysis Kashan Region, Journal of Research in Iran Grassland and Desert, Vol. 27, No. 3, 465 -445, 2010.

[7] M. Rezaei Moghaddam, Kh. Valizadeh Kamran, H. Rostamzadeh. Evaluating the Performance of MODIS Data for Estimating Drought (Case Study: The lake's basin), Journal of Geography and Environmental Sustainability, Vol. 2, No. 5, 52-37, 2012.

[8] M. Santini, G. Caccamo, A. Laurenti, S. Noce, R. Valentini. A Multi-Component GIS Framework for Desertification Risk Assessment by an Integrated Index, Journal of Applied 
Geography, Vol. 30, No. 3, 394-415, 2010.

[9] L. Salvati, M. Zitti, T. Ceccarelli, L. Perini. Developing a Synthetic Index of Land Vulnerability to Drought and Desertification, Journal of Geographical Research, Vol. 47, No. 3, 280-291, 2009

[10] A.S. Hadeel, J. Mushtak, X. Chen. Application of Remote Sensing and GIS in the Study of Environmental Sensitivity to Desertification (case study in Basrah Province, southern part of Iraq), Journal of Appl. Geomat, Vol. 2, No. 3, 101-112, 2010

[11] L. Salvati, D. Angelis, s. Bajocco, A. Ferrara, m. Barone. Desertification Risk Long-Term Land- Use Changes and Environmental Resilience (Case Study in Basilicata, Italy), Journal of Scottish Geographical, Vol. 129, No. 2, 85-99, 2013.

[12] A. Sepehr, C. Zucca, M. Nowjavan. Desertification Inherent Status Using Factors Representing Ecological Resilience, Journal of Environment and Climate Change, Vol. 4, No. 3, 279-291, 2014.

[13] P. Molinari. A Geographic Information System GIS with Integrated Models: A New Approach for Assessing the Vulnerability and Risk of Desertification in Sardinia (Italy), Journal of Global Bioethics, Vol. 25, No. 1, 27-41. 2014.

[14] V. Krishnan, R. Murugaiya, R. Shanmugham, M. Mariappan. Assessing the Impact of Natural Factors on Desertification in Tamilnadu, India using Integrated Remote Sensing, $1^{\text {st }}$ International Electronic Conference on Remote Sensing, 1-16, 2015.

[15] L. Salvati, A. Mavrakis, A. Colantoni, G. Mancino, A. Ferrara. Complex Adaptive Systems, Soil Degradation and Land Sensitivity to Desertification: A Multivariate Assessment of Italian Agro-Forest Landscape, Journal of Science of the Total Environment, Vol. 521-522, No. 15, 235-245, 2015.

[16] R. Becerril-Pina, C. Diaz-Delgado, C. Mastachi-Loza, E. Gonzalez-Sosa. Integration of Remote Sensing Techniques for Monitoring Desertification in Mexico, Journal of Human and Ecological Risk Assessment, Vol. 22, No.1323-1340, 2016.

[17] M. Lamchin, J. Lee, W. Lee, E. Lee, M. Kim, CH. Lim, H.Choi, S. Kim. Assessment of land cover change and desertification using remote sensing technology in a local region of Mongolia, Journal of Advances in Space Reserch, Vol. 57, No. 64-77, 2017.

[18] M.K. Boitt, P.A. Odima. Assessment of Desertification Dynamics in Machakos County, Kenya, Journal of Geoscience, Vol. 5(2), No. 40-43, 2017.

[19] ISO, 2006. ISO 14040 International Standards. Environmental Management - Life Cycle Assessment - Principles and Framework. International Organisation for Standardization, Geneva, Switzerland, 2006.
[20] N. Abbaszade Tehrani, N. Saberi. Seasonal Land Cover Change Assessment Using Remote Sensing Data Analysis, International Conference on the 3th Environmental Planning Management, No. 596-616, 2013.

[21] T. Tervonen, A. Sepehr, M. Kadzinski. A Multi-Criteria Inference Approach for Anti-Desertification Management, Journal of Environmental Management, Vol. 162, No. 1, 9-19, 2015

[22] F. Hadian, R. Jafari, H. Boshra, S. Soltani. Monitoring the Impact of Rainfall on Vegetation Changes Using Remote Sensing Techniques for a Period of 21 Years (Case Study: Semirom and Lordegan), Journal of Rangeland and Watershed, Vol. 66, No. 4, 621-632, 2013.

[23] A.R Sepaskhah. Collecting Rain to Rainfed Tree, Journal of Technical Publication, Vol. 44, No. 6, 19-31, 1982

[24] M. Keshavarz, M. Vazifehdust, A. Alizadeh, A. Asadi. Extraction and Routing Soil Moisture to Help MODIS Satellite Data (Case Study: Isfahan Province), Journal of Iran Irrigation and Drainage, Vol. 5, No. 2, 219-209, 2011.

[25] M.N. Khan, V.V. Rastoskuev, Y. Sato, S. Shiozawa. Assessment of Hydrosaline Land Degradation by Using a Simple Approach of Remote Sensing Indicators, Journal of Agricultural Water Management, Vol. 77, NO. 1-3, 96-109, 2005.

[26] M. Mehta, V.Le. Anh, S.K. Saha, Sh. Agrawal. Evaluation of Indices and Parameters Obtained from Optical and Thermal Bands of Landsat 7 ETM+ for Mapping of Salt- Affected Soils and Water-Logged Areas, Journal of Geoinformatics, Vol. 12, No. 4, 9-16. 2012.

[27] L. Du, Q. Tian, T. Yu, Q. Meng, T. Jancso, P. Udvardy, Y. Huang. A Comprehensive Drought Monitoring Method Integrating MODIS and TRMM Data, International Journal of Applied Earth Observation and Geoinformation, Vol. 23, No. 22, 245-253, 2013.

[28] M. Momeni. New Issues of Operation Research, Tehran University, 2007.

[29] M.T. Jabbar. Assessment of Soil Salinity Risk on the Agricultural Area in Basrah Province, Iraq, Using Remote Sensing and GIS Technique, Journal of Earth Science, Vol. 23, No. 6, 881-891, 2012.

[30] A. Allbed, L. Kumar. Soil Salinity Mapping and Monitoring in Arid and Semi-Arid Regions Using Remote Sensing Technology, Journal of Advances in Remote Sensing, Vol. 2, No. 4, 373-385, 2013.

[31] M. Mahamane, V. Hochschild, A. Schultz, J. Kuma. Monitoring Desertification in the Tillabéry Landscape (Sahel Region) Using Change Detection Methods and Landscape Metrics, International Journal of Applied Research, Vol. 1(10), No. 315-321, 2015. 